\title{
Integration Mode of Education Resources for College Students' Socialist Core Value System from the Perspective of New Media
}

\author{
Wei Ling \\ Yunnan Normal University, Kunming 650500,China
}

Keywords: New media; socialist core value system; Resource integration mode; Fuzzy evaluation method

\begin{abstract}
New media uses its diversified way to show people a rich image of the education theme and content, as well as breaking the traditional geographical and temporal and spatial limitations, conveying a wealth of resources for the audience with the vast amounts of knowledge and information. socialist core value in such a stage with so much concern will be with the integration of new media to achieve a fundamental change, and new media in socialist core value resource integration can not only enrich the socialist core value way to expand the educational approaches of socialist core value, beautify the environment of socialist core value, but also integrate socialist core value platform for resource sharing and optimization configuration. We should fully use new media technologies to effectively apply it to socialist core value system resource integration, so that socialist core value system is no longer limited to a single mentoring taught, but by means of new media, with a visual and auditory feast effects to realize college students' socialist core value cultivation, which can not only speed up and improve the efficiency, but also realize sharing and utilization of social resources and better able to achieve economic and social optimization.
\end{abstract}

\section{Introduction}

While in pursuit of the all-round development, there is a growing concern in the socialist core value of college students, which makes people constantly concerned about the socialist core value in the traditional system of socialist core value . socialist core value in colleges and universities is not very optimistic without any ideal effect[1]. What are the aspects of socialist core value resources of colleges and universities and how to make these socialist core value resources to maximize the utility of play would need to integrate socialist core value resources of the college. These new technologies bring new media in the era of rapid development of today's the society computer network technology and information communication technology, and media characteristics is across time and space[2-4]. These new media are not only presented in the form of text, but more is illustrated in the form of video, audio, images, and other aspects. The new media is not only able to achieve socialist core value system resource integration, and socialist core value in colleges more advanced methods and technology, lift the socialist core value of students interested in shaping the atmosphere of socialist core value, and better able to bridge the communication gap between the universities and social institutions, and the dissemination of information, and shorten the distance. It can also to achieve the interaction between each other, make the free transfer of information resources and learning, achieve spatial and temporal coexistence of old and new media complementary, and jointly promote the progress to realize the diversity of information dissemination to achieve efficient diversity of socialist core value and diversification[5].

\section{Literature overview and research methods}

The new media is only relative to specific media, reflecting an era of development and progress, which is the old and new media's constantly updated alternating process and incremental progress. New media is the most high-end and state-of-the-art picture, text or video, audio-visual technology, heritage and development forward on the basis of the old media. For example, the television had just come out, then people hailed the TV as new media; the emergence of computer network technology is a new media; the emergence of mobile media is a new media. New media with the progress of the 
times and technology continue to produce new media is a combination of computer network technology, information technology, digitization and communication technology support, text, images, audio, video transmission, bearing new media and technology is the ability to forward the information needed by a wide audience, featuring a collection of other media.

socialist core value is the focus of the college and the community in general. What are university socialist core value resources? How to take advantage of the socialist core value resources is our focus and will continue to think and solve. Some scholars have pointed out that the socialist core value resource contains not only the combination of manpower and material resources as well as financial. But some scholars say that socialist core value resources is composed by the culture of socialist core value, the system of rules, community, material and human resources. But it also gives us an idea means that socialist core value resource is a rich and broad system[6]. This paper argues in socialist core value resources are composed by the three parts: the material resources, cultural resources, as well as human resources of colleges and universities. Material resources of colleges and universities are mainly reflected in the college's educational infrastructure, multimedia, teachers, cross, infrastructure, etc.. The college cultural resources of the universities are to create a culture of learning for students, the comprehensive development of the workplace and the environment. University human resources are mainly college things and activities for the students of party building, group organization, and student management. Then we need to integrate and use these various resources.

This article uses fuzzy evaluation method, first make clear the evaluation of the evaluation factor set $\mathrm{F}$, then we make the evaluation index factors as $\mathrm{m}$, and then we can get[7]

$\mathbf{F}=\left(f_{1}, f_{2}, \ldots . . f_{m}\right)$,

and $f_{i}$ represents individual evaluation factor indicator.

Then we have to determine the evaluation set of indicators corresponding to the evaluation factor $\mathrm{W}$, and the evaluation level is determined as $\mathrm{n}$, then we can get[8]

$W=\left(w_{1}, w_{2}, \ldots . . w_{n}\right)$

Third, through expert evaluation factor indicator scoring, we make claer the weight set A.

Fourth, we build the evaluation matrix[9]

$$
T=\left[\begin{array}{cccc}
t_{11} & t_{12} & \ldots & t_{1 n} \\
t_{21} & t_{22} & \ldots & t_{2 n} \\
\vdots & \vdots & & \\
t_{m 1} & t_{m 2} & \ldots & t_{m n}
\end{array}\right],
$$

and $t_{i j}$ is the evaluation factor index $f_{i}$ corresponding to the jth evaluation value.

Fifth, we make this comprehensive evaluation.[10]

$$
\left(b_{1}, b_{2}, \ldots, b_{n}\right)=\left(a_{1}, a_{2}, \ldots a_{m}\right) \times\left[\begin{array}{cccc}
t_{11} & t_{12} & \ldots & t_{1 n} \\
t_{21} & t_{22} & \ldots & t_{2 n} \\
\ldots & \ldots & \ldots & \ldots \\
t_{m 1} & t_{m 2} & \ldots & t_{m n}
\end{array}\right]
$$

Among them,

$$
b_{j}=\vee \underset{i=1}{\left(a_{i}^{m} \wedge t_{i j}\right)}
$$

The last step is the normalized analytical processing for the data.

\section{The establishment of the socialist core value system resources evaluation system from the new media perspective}

socialist core value system in the new media perspective resource integration not only reflected the socialist core value based on the idea of education, and more is that the existing socialist core value 
resources can be fully effective resources to achieve optimal configuration, which makes socialist core value more fully realized play, helping to train the students' socialist core value ideological quality. The socialist core value system resource integration lies not only in the existing resources to achieve the full depth of the excavation and development, but also in the light of the new media, a new perspective to explore the socialist core value resources optimal the binding equilibrium point, socialist core value system resources can be optimized play, to achieve effective integration of socialist core value resources is much greater than single socialist core value resources superimposed effect.

This paper discusses mainly from five aspects of socialist core value system: cultural, institutional, material, socialist core value, and network building evaluation system of socialist core value. System embodies socialist core value is mainly focus on the student body reasonable, psychological as well as honest and trustworthy education and humanistic spirit atmosphere of the evaluation in the evaluation of the university legal, ethical, regulatory, and environmental protection, training and education; belief is mainly reflected in the people of faith, patriotism and concern such as international and domestic affairs. The substance is more concerned about care activities of daily code of conduct, and actively participation in community activities. The network is in the application of the new media.

First, we evaluate each of the five factor indicator sequentially. Through cognitive evaluation, we obtain[11]

$F_{\text {System }}=\left(f_{1}, f_{2}, f_{3}, f_{4}\right)=$ (Rules, Laws, Re gulation, Internation, Environmentalprotection)

and the corresponding evaluation set $\mathrm{W}$ is:

Table 1 Single evaluation factor indicator assessment form

\begin{tabular}{|l|l|l|l|l|}
\hline & f1 & f2 & f3 & f4 \\
\hline $\mathrm{w}$ & 0.9 & 0.85 & 0.8 & 0.95 \\
\hline
\end{tabular}

Table 1 shows that a critical evaluation of a teacher for the students' socialist core value cognition scores are: $0.9,0.85,0.8,0.95$. This can be written as:

$\mathrm{T}_{1}=(0.9 、 0.85 、 0.8 、 0.95)$

Correspondingly, after making sure other evaluation factor indicators, we can get:

$$
T_{\text {system }}=\left[\begin{array}{cccc}
0.9 & 0.85 & 0.8 & 0.95 \\
0.8 & 0.75 & 0.75 & 0.9 \\
0.9 & 0.8 & 0.8 & 0.85 \\
0.95 & 0.9 & 0.9 & 0.9
\end{array}\right]
$$

So, we can draw a comprehensive evaluation of cognitive.

$B_{\text {system }}=A_{1} T_{\text {system }}=(0.4,0.4,0.3,0.3) \times\left[\begin{array}{cccc}0.9 & 0.85 & 0.8 & 0.95 \\ 0.8 & 0.75 & 0.75 & 0.9 \\ 0.9 & 0.8 & 0.8 & 0.85 \\ 0.95 & 0.9 & 0.9 & 0.9\end{array}\right]$

$=(0.87,0.80,0.815,0.875)$

Then after other evaluation we obtain:

$$
\begin{aligned}
& B_{\text {culture }}=(0.915,0.85,0.765,0.86) \\
& B_{\text {Material }}=(0.91,0.84,0.965,0.89) \\
& B_{\text {ethics }}=(0.79,0.865,0.76,0.815) \\
& B_{\text {network }}=(0.94,0.87,0.84,0.83)
\end{aligned}
$$

Finally, after the normalization of the indicator of each factor, we can get:

$\mathrm{B}^{\prime}=(0.2033,0.2127,0.2090,0.1950,0.2120)$

This indicates that college students rank first in the area of socialist core value resources, accounting for $21.27 \%$, followed by the network education, accounting for $21.20 \%$, in the third of the material resources, the final is ethics resources, accounting for 19.50\%[12]. These accounted for less; college for five aspects of educational resources are more concerned about a variety of socialist core 
value is relatively flat. But the importance of material and institutional resources is to strengthen ethics, network utilization and cultural resources. This requires more use of new media.

socialist core value system resource integration model analysis from new media perspective

Student socialist core value goal is not only to achieve human development, and ultimately to the development of the society. Not only to achieve the ideal and faith education, innovation, education, scientific spirit, integrity education, psychological education. These need by means of socialist core value in different media. socialist core value system from the new media perspective needs resource integration of university cultural construction, material, system construction, and ethics as well as the network of educational resources to be used effectively (Figure 1). Then through new media we can realize the visual and auditory impact, the span of time and space, and the free dissemination of information and innovation development, and the acceleration of the socialist core value of the students.

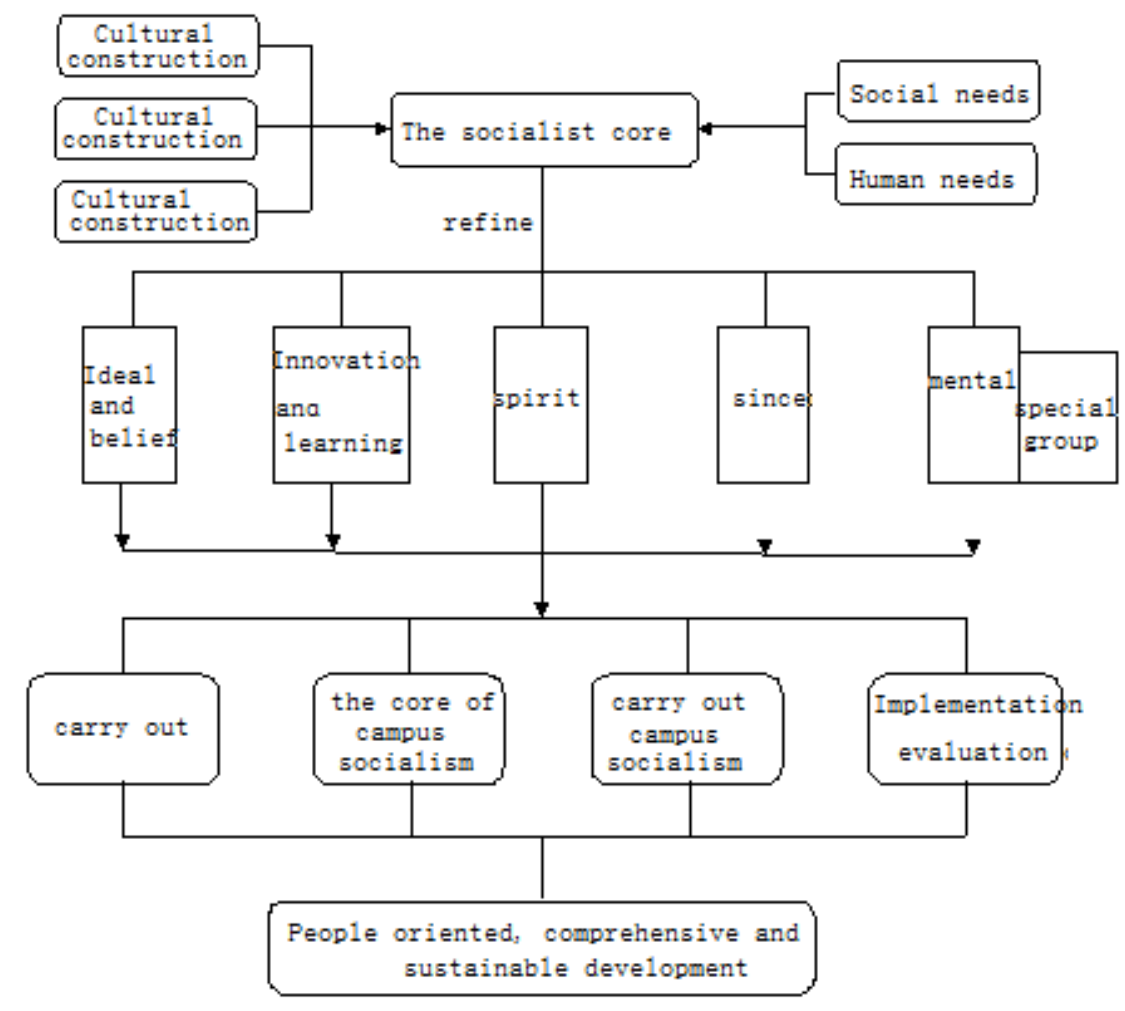

Fig.1 socialist core value system resource integration model Figure from new media perspective

Socialist core value system resource integration model from the new media perspective needs making the university's cultural, material, system, and socialist core value, and network resources optimization configuration and integration at the same time, strengthen the campus socialist core value evaluation system is the establishment of a sound and effective implementation of the university socialist core value model evaluation and analysis of the full range of the guidance of the socialist core value of the university, people-oriented culture comprehensive and sustainable development of the students.

Socialist core value systemation resources are the focus of the community and it is also the focus of this article on how to realize the resources of the socialist core value systemation optimization, so that it can play the biggest role. The main content of the article is in the new media and socialist core value systemation resources, focusing on college students in socialist core value evaluation to build socialist core value evaluation system for colleges and universities. Meanwhile, we understand the socialist core value status quo and through fuzzy evaluation method statistical analysis to know the status of socialist core value education, and target to the establishment of a new media perspective of the socialist core value systemation resource integration mode, use resources in the society, network as well as colleges and universities to realize resources' effective sharing, in order to achieve the integration of resources and the optimal configuration of resources. 


\section{Acknowledgments}

The work was supported by the Philosophy and Social Sciences Planning Project of Yunnan Province with the project number QN2015010 and the project name Research on the Influence and Countermeasures of Contemporary Chinese Non-Marx's Social Thought on College Students' Thoughts and Behaviors.

\section{References}

[1] Celebi, Aysun Tasyapi, Kefeli, H.Cem, Erturk, Sarp. Video coding, web browser and multimedia transmission applications on texas instruments DaVinci platform. The 2007 IEEE 15th Signal Processing and Communications Applications, 2007.

[2] S.F. Wang, Z.Q. Huang, Y.B. Hou. A design of low-cost low-bandwidth mobile video surveillance system based on DM6446. The 2007 International Conference on Wireless Communications, Networking and Mobile Computing, WiCOM 2007.

[3]Jung,Sung-In,Lee,Cheol-Hoon. A continuous stream service and high service availability mechanism for continuous media servers. The sixth International Conference on Advanced Communication Technology: Broadband Convergence Network Infrastructure, 2004.

[4]Chakareski, Jacob, Frossard, Pascal. Adaptive systems for improved media streaming experience [J]. IEEE Communications Magazine, 2013, 45(1): 77-83.

[5] B. Liu. MedSMan: A live multimedia stream querying system. Multimedia tools and applications, 2014, 38(2): 209-232.

[6] D.G. Li, J. Chen, Z.H. Wu. Research and development of in-vehicle information platform based on Arm-Linux. Journal of Zhejiang University (Engineering Science), 2014, 40(9): 1531-1535.

[7]Goodacre, Joh, Sloss, Andrew N. Parallelism and the ARM instruction set architecture. Computer, 2015, 38(7): 42-50.

[8] S.Y. Wang, J. Chen, S.Q. Zhang. Embedded Linux system design for hardware/software co-development. Journal of Tsinghua University, 2015, 45(7): 973-976.

[9]Texas Instruments Embedded Processors Wiki.DM6446x designer's resource guide [EB/OL]. http://wiki.davincidsp.com/index.php?title=DM644x_designer\%27s_resource_guide. 